\title{
Dyeing in catalase-treated bleaching baths
}

\author{
Tzanko Tzanov, ${ }^{a}$ Silgia Costa, ${ }^{a}$ Georg M Guebitz, ${ }^{b}$ \\ Artur Cavaco-Paulo ${ }^{a, *}$ \\ ${ }^{a}$ University of Minho, Textile Engineering Department, 4800 Guimaraes, Portugal \\ Email:artur@eng.uminho.pt \\ ${ }^{b}$ Technical University of Graz, Institute of Microbiology, 8010 Graz, Austria
}

\begin{abstract}
The conventional rinsing after bleaching to remove the residual hydrogen peroxide, harmful to the dyes either in solution or on the fabric, was replaced by enzymatic cleaning using catalases. The catalasetreated bleaching liquor was reused for dyeing. Though no hydrogen peroxide was detected after the enzymatic process, the bleaching bath composition caused unacceptable colour changes on dyed fabrics. By varying the parameters of the dyeing process - dye, salt, alkali and enzyme concentrations the colour difference could be reduced significantly and a good dyeing result could be achieved.
\end{abstract}

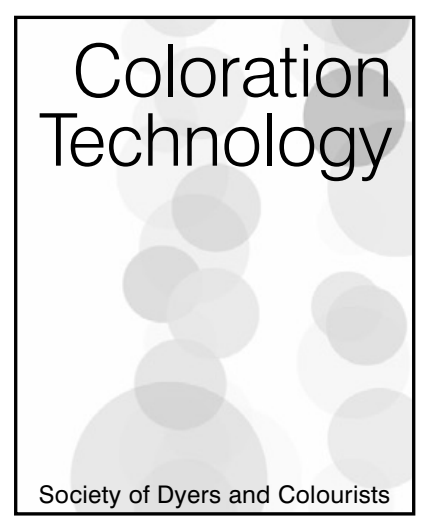

\section{Introduction}

The conventional textile processing technology of cellulose materials, e.g. the bleaching-washing-dyeing cycle, involves high levels of water consumption and increased loading of dyehouse wastewater with hydrolysed reactive dyestuffs. Whilst the latter problem can be resolved to some extent by improvement of dye stability against hydrolysis, or by modification of cellulose material with new reactive agents to enhance its dyeability $[1,2]$, the actual need for a washing process after bleaching has, up to now, not been considered.

Hydrogen peroxide is at present the most commonly used bleaching agent for all natural fibres of vegetable or animal origin and this technology is ecologically acceptable and economically feasible. The washing process after bleaching is a step that consumes large amounts of water, since any residual hydrogen peroxide has to be removed to avoid problems in subsequent dyeing processes. The presence of hydrogen peroxide in the dyebath can cause decolourisation of reactive dyes which are sensitive to oxidation. It has already been shown that even minor modifications of the dye molecule can result in colour loss $[3,4]$. In general, dyes exhibit different resistance towards oxidising agents, both in the liquor and on the textile material. However, even small colour changes can render the dyed fabrics commercially unacceptable due to the stringent contemporary quality requirements.

These demands, which at first glance may appear contradictory, i.e. to reduce water consumption by shortening or eliminating the washing cycle after bleaching whilst at the same time ensuring good reproducibility of dyeing, may be met by adopting modern biotechnology. Catalase is an enzyme widely distributed in nature and well known for its ability to catalyse the conversion of hydrogen peroxide to water and gaseous oxygen. This enzyme occurs in almost all aerobically respiring organisms and serves to protect the cells from the toxic effects of hydrogen peroxide. It has found numerous applications in food science, industrial food production and medical and analytical fields [5,6]. Commercial products containing catalase for textile applications are also available. These have been used to decompose residual hydrogen peroxide in fabric prior to dyeing, and are normally applied after draining the bleaching bath and refilling it with fresh water [7]. However, limitations are imposed by the low temperature and alkali stability of the enzyme.

This study is an attempt to ensure efficient reduction in the levels of water consumption, avoiding the extensive washing process of cellulose fabrics after bleaching. To achieve this purpose, the bleaching bath, containing the fabric, was directly treated with catalase to destroy the residual hydrogen peroxide and then reused for dyeing with reactive dyes. The opportunity to afford a new, unconventional dyeing technique, i.e. dyeing within the bleaching bath, was investigated.

\section{Experimental}

\section{Materials and methods}

Two reactive dyes with different chemical structures were used in this study. These were Evercion Blue HEGN (CI Reactive Blue 198), a monochlorotriazine dye, and Everzol Brillant Orange 3R (CI Reactive Orange 16), a vinylsulphone dye. These dyes were applied in an 'all-in' dyeing process on previously bleached $100 \%$ cotton woven fabrics. The fabrics were bleached following the recipe: silicate (BDH), 3.5\% owf; soda ash (Merck), 1\% owf; sodium hydroxide (Merck), $1 \%$ and $35 \%$ hydrogen peroxide (Sigma), $4 \%$ owf; $90{ }^{\circ} \mathrm{C}$ for $60 \mathrm{~min}$.

The bleaching bath was treated with $4 \mathrm{ml} / \mathrm{l}$ of the catalase product Eurozim OXI-500 (INPAX, $0.29 \mathrm{mg} / \mathrm{ml}$ protein [8]) for $15 \mathrm{~min}$. The presence of hydrogen peroxide in the bleaching bath after treatment with catalase was detected with analytical test strips supplied by Merck (Merckoquant Peroxide-Tests: 1.10011.0001, 1.10081.0001 and 1.10337.0001).

The dyeings were performed at $3 \%$ owf of dye. This depth of shade was chosen because dyeing in lighter shades, e.g. 1 and $2 \%$ owf, gave too large a colour difference. Dyeings with Reactive Blue 198 were carried out in the presence of Glauber's salt $60 \mathrm{~g} / \mathrm{l}$ and soda ash $20 \mathrm{~g} / \mathrm{l}$ at a dyeing temperature of $80{ }^{\circ} \mathrm{C}$ for $60 \mathrm{~min}$, and for Reactive Orange 16 with Glauber's salt $50 \mathrm{~g} / \mathrm{l}$ and soda ash 
$20 \mathrm{~g} / \mathrm{l}$ at $60{ }^{\circ} \mathrm{C}$ for $60 \mathrm{~min}$. Both dyeing and bleaching were carried out in an Ahiba Spectradye (Datacolor) dyeing apparatus at a liquor ratio 20:1. Each dyeing experiment was repeated three times. Dyed fabrics were washed-off at the same liquor ratio with non-ionic detergent Hostapal CV for $30 \mathrm{~min}$ at $90{ }^{\circ} \mathrm{C}$ to remove the unfixed dye.

The catalase enzyme activity was measured following the decomposition of hydrogen peroxide by a UV spectrophotometric assay (Unicam He $\lambda$ ios UV-Vis spectrophotometer) [9]. The colour differences of the dyed fabrics were determined using a reflectance measuring apparatus (Datacolor) according to the CIELAB colour difference concept at standard illuminant $\mathrm{D}_{65}$ (LAV/Spec. Excl., d/8, $\left.\mathrm{D}_{65} / 10^{\circ}\right)$.

\section{Results and Discussion}

Effect of residual peroxide concentration and bleaching bath composition on colour of dyed fabrics

\section{Residual peroxide}

Prior to treatment of the bleaching bath with catalase, the minimum peroxide content having no effect on the colour of the dyed fabrics was determined. Various peroxide concentrations in the dyebath, ranging from $0.001-0.3 \%$ owf, were applied and some of the results are plotted in Figure 1 against the total colour differences $\left(\Delta E^{*}\right)$. Dyeing experiments were performed in a standard dyebath containing a known quantity of hydrogen peroxide.

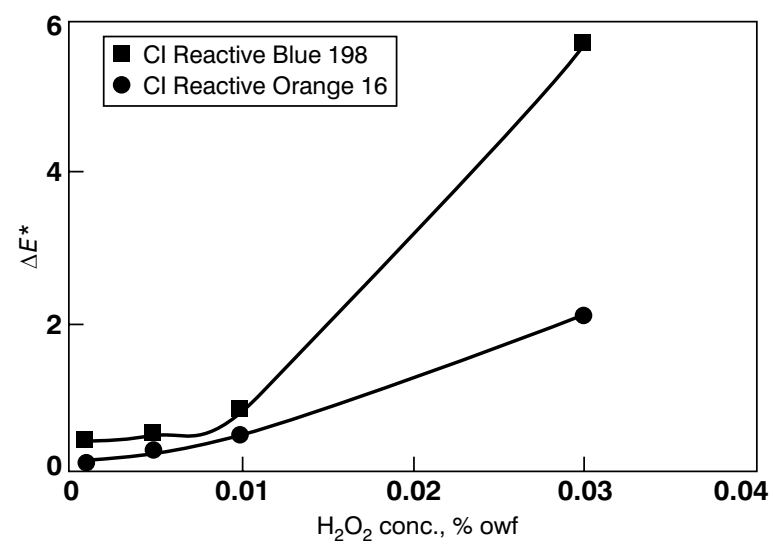

Figure 1 CIELAB colour differences of dyed fabrics at different concentrations of hydrogen peroxide in the dyebath

It is apparent from the results in Figure 1 that the presence of hydrogen peroxide in the dyebath is harmful to the reactive dyes used and provoked differences between the colour of the samples and the colour of the standard (dyed without peroxide) even in very low concentration. However, the acceptability of these differences depends on the adopted colour difference tolerance. Concentrations of peroxide up to $0.01 \%$ owf were not crucial for dyeing, assuming a $\Delta E^{*}$ of 1 CIELAB unit as acceptable, although there is not yet commonly accepted colour tolerance for all colours [10]. Normally, the colour difference tolerance is previously defined according to consumer demands and depends on the colour itself $[11,12]$.
Bleaching bath composition

The multi-component bleaching bath composition and the supplementary added catalase are the main problems in achieving reproducibility of dyeing when reusing the bleaching effluent. Interaction between the reactive dye and the bleaching components would be expected, resulting in dye aggregation and restricted diffusion of the dye through the dyeing solution onto the fibre surface. The exact composition of the bleaching liquor has not been defined up to now. Besides the bleaching chemicals such as alkali, silicate and peroxide present in the bleaching bath, it is claimed that oil and waxes, pectins, proteins, organic acids, mineral matter, natural colouring-matter and sizing agents have also been extracted from cotton under such conditions $[13,14]$.

In order to study the influence of the bleaching bath components on the colour of fabrics dyed in the bleaching liquor, a set of experiments were carried out in which the composition of a standard dyebath was varied. When the bleaching effluent composition was simplified and the presence of catalase, peroxide and silicate were considered separately, each of these components provoked colour differences of varying magnitude when added to a standard reactive dyebath made with water (Figure 2). The colour difference caused by the enzyme was greater than that caused by the silicate but by far the greatest was that caused by hydrogen peroxide. It is therefore imperative that any residual hydrogen peroxide must be destroyed prior to dyeing.

Catalase is a tetrameric haemin-enzyme, which contains four ferriprotoporphyrin groups per molecule [9]. Chelating agents may remove the iron atom from the haem group of catalase and thereby inactivate it [15]. Bleach formulations usually contain sequestering agents, such as silicates, phosphates or oxalates. It can be supposed that the sodium silicate (waterglass) might alter catalase activity, when the enzyme is added to the bleaching bath, due to the sequestering properties of the silicate [14]. This classical hydrogen peroxide stabiliser acts as an anticatalyst. Catalysts, which decompose hydrogen peroxide, are inserted into the waterglass colloids and thereby are inactivated. In our experiment enzyme activity (measured in phosphate buffer $\mathrm{pH} 7$ ) decreased slightly from 5.5 to $5.4 \mu \mathrm{mol} / \mathrm{min}$ in the presence of silicate. On the other hand deposition of the silicate on fabric surface could be a possible reason for non-uniformity of coloration.

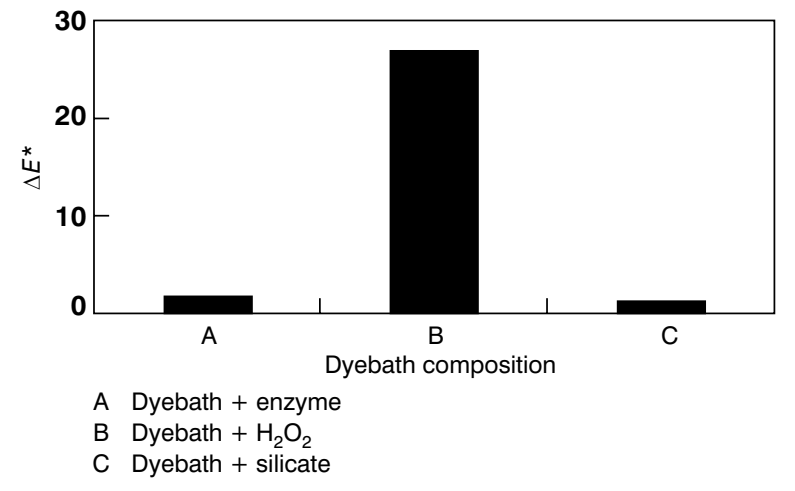

Figure 2 Colour differences of fabrics dyed with Reactive Blue 198 in the presence of enzyme, hydrogen peroxide or silicate 
Alkalinity of bleaching and dyeing baths

The bleaching process with hydrogen peroxide proceeds by dissociation into $\mathrm{H}^{+}$and perhydroxy ions $\left(\mathrm{HOO}^{-}\right)$in alkaline medium. In our experiments the initial $\mathrm{pH}$ of the bleaching solution was about 11.5 , and by the end of the bleaching process the $\mathrm{pH}$ had decreased to 10.5. Alkaline conditions are indispensable for the dyeing of cellulose textile materials with reactive dyes, with the $\mathrm{pH}$ of a standard dyebath as prepared according to the recipes described being $\sim 11$ (Table 1). This poses the question whether dyeing can be performed in the bleaching effluent due to its alkalinity levels as the $\mathrm{pH}$ of the 'normal' dyebath is higher than that of the bath prepared with bleaching effluent.

Table 1 Alkalinity of the bleaching and reactive dyeing baths

\begin{tabular}{ll}
\hline Solutions & pH value \\
\hline & \\
Bleaching effluent & 10.5 \\
Bleaching effluent + dye & 10.3 \\
Bleaching effluent + dye + alkali & 10.9 \\
Bleaching effluent + dye + alkali + salt & 10.7 \\
Bleaching effluent + dye + alkali + salt + enzyme & 10.8 \\
Dyebath without dye & 11.2 \\
Dyebath with dye & 11.1 \\
\hline
\end{tabular}

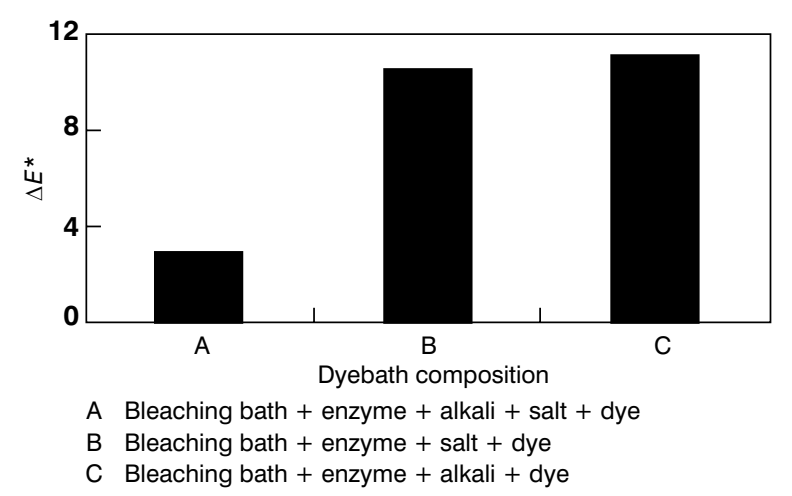

Figure 3 Colour differences of fabrics dyed with Reactive Blue 198 in the bleaching bath with the addition of enzyme, alkali and/or salt

The colour difference for fabrics dyed with Reactive Blue 198 in the bleaching bath with the addition of catalase, alkali (soda ash) and Glauber's salt, were compared with those samples dyed only with the addition of either alkali or salt (Figure 3). It is apparent that the colour difference for samples dyed without the addition of alkali or salt were greater than those dyed with all the standard ingredients. Therefore the addition of alkali is a necessary step, which improves dye fixation. Even a small difference in the alkalinity of the dyebath $(\Delta \mathrm{pH}=0.5)$ causes a significant colour change in dyed samples. Variation of the fixation reaction with changes in external $\mathrm{pH}$ is related to the degree of ionisation of the cellulose hydroxy groups in the fibre itself. The salt is also a necessary component to ensure dye exhaustion, promoting the physicochemical adsorption of the dye.
Approaches for application of catalase to the bleaching bath

Two approaches for the application of catalase following the bleaching process were undertaken and the effect on the subsequent dyeings compared. The traditional approach involved draining the bleaching bath and refilling it with fresh water followed by the addition of enzyme. In the alternative approach the enzyme was added directly to the bleaching bath containing the fabric, either with or without neutralisation of the bath. The first approach is adopted in textile finishing since all the hydrogen peroxide is never completely consumed during a normal bleaching cycle. When the bleaching liquor is run-off the fabric is still saturated with peroxide-containing bleaching solution.

As might have been expected, the results showed that the conventional method of application gave the best results (Figure 4). Interestingly, comparing the second method and its variations, neutralising the bleaching bath with acetic acid prior to the application of catalase did not give improved colour yield in dyeing than adding the enzyme to the bath without any $\mathrm{pH}$ adjustment. However, it can be seen that the Reactive Blue 198 dye gave better results in both cases.

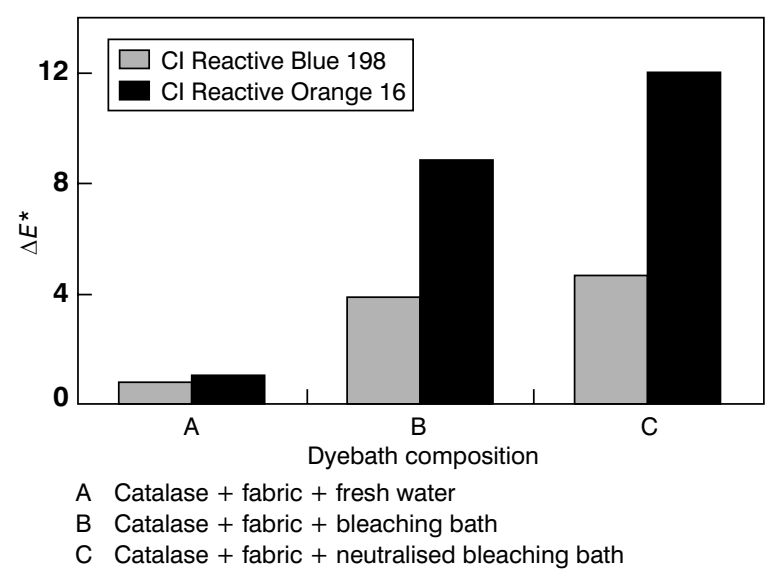

Figure 4 Different approaches for the application of the catalase to the bleaching bath prior to dyeing

In all the experiments described, the catalase was added when the bleaching bath had cooled to $30{ }^{\circ} \mathrm{C}$. This temperature was chosen since the trials where the catalase was added immediately after bleaching at $90{ }^{\circ} \mathrm{C}$ or after the bath was cooled to $60{ }^{\circ} \mathrm{C}$ resulted a in considerable shade change in the dyed fabrics (Figure 5). Obviously at high temperatures, where the bleaching effluent was not cooled, the catalase was inactivated and the hydrogen peroxide was not completely destroyed. This observation differs from the temperature profile of catalase activity, obtained in phosphate buffer at pH 7 and with an incubation time of $30 \mathrm{~min}$ (Figure 6). From this profile, it might have been expected that the addition of catalase to the bleaching bath at $60{ }^{\circ} \mathrm{C}$ would produce better results. In practice, the catalase applied under these conditions was not efficient enough to degrade all the residual peroxide. This decrease of the enzyme efficiency could be attributed to the complexity of the bleaching bath composition. Considering that the silicate slightly altered 
the enzyme activity, when added alone to phosphate buffer solution, the presence of the combination of substances in the bleaching effluent gives a complex effect, which could not be evaluated separately.

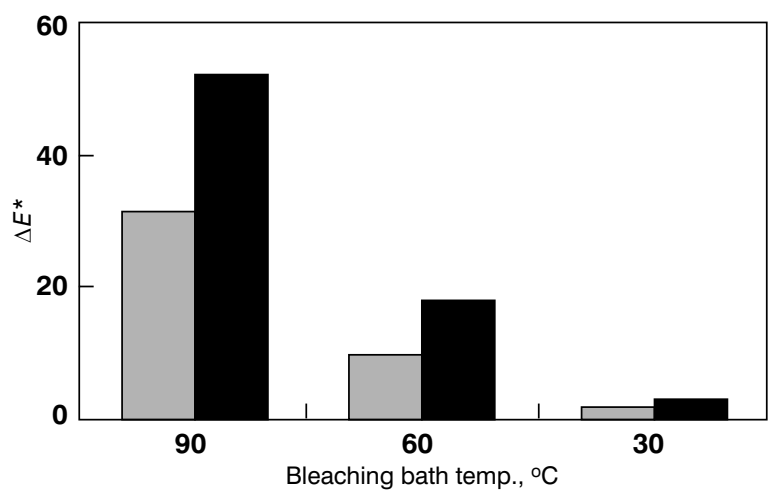

Figure 5 Dyeing in the bleaching bath following the addition of catalase at different temperatures; for key see Figure 4

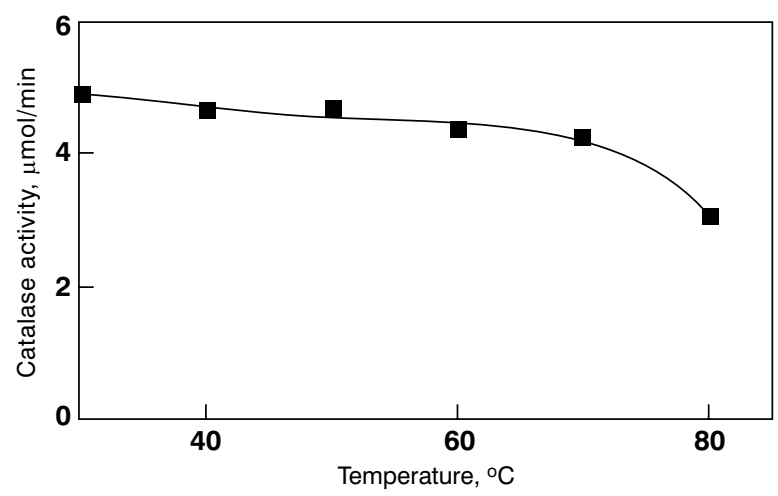

Figure 6 Temperature profile of catalase activity

\section{Factors influencing dye up-take and fixation in the bleaching bath}

There are a number of factors that influence dye up-take and fixation when dyeing is carried out in the bleaching bath. These include concentrations of the dye, alkali, electrolyte and enzyme, and the ability of the catalase to convert the residual peroxide to water, neglecting the nondefined substances extracted from cellulose during bleaching. The influence of the above parameters was quantified in terms of total colour difference between dyed fabrics and the standard. The concentration of each of these dyeing components was varied with the aim to compensate the intrinsic colour difference coming from the bleaching bath composition.

\section{Dye concentration}

Normally, the colour yield is proportional to the dye concentration. In this study it was found that by increasing the dye concentration up to a certain limit it was possible to compensate the colour difference between fabrics dyed in a dyebath prepared with fresh water and with catalasetreated bleaching effluent. In the latter case, a 20\% increase in dye concentration was sufficient to achieve consistency of colour within 1 CIELAB unit (Figure 7). A further increase in dye concentration provoked higher colour

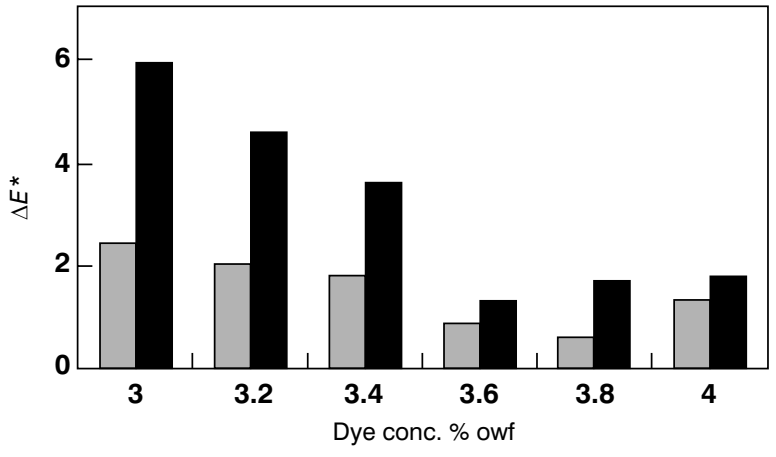

Figure 7 Dyeing in the catalase-treated bleaching bath with increasing dye concentration; for key see Figure 4

differences as the colour of the dyed sample moved to a deeper shade (the chromaticity increased). However for bright colours like those imparted with Reactive Orange 16 , where the initial colour difference was greater, it was more difficult to set the colour difference value within the defined tolerance interval.

\section{Electrolyte concentration}

When the amount of electrolyte in a dyebath is increased, the electrostatic repulsion forces decrease which facilitates the adsorption of the dye onto the substrate. Increasing the salt concentration is usually related to increased dye uptake [16]. On the other hand, by increasing the salt concentration, respectively the ionic strength of the dyeing solution can also promote dye aggregation.

Experiments carried out with increasing salt concentration in the dyebath, prepared with catalase-treated bleaching effluent, showed that the colour difference between the conventionally dyed fabric and the fabric dyed reusing the bleaching effluent can be partially reduced (Figure 8). However, an increase of more than 25\% salt content renders the dyeing process quite environmentally unfriendly.

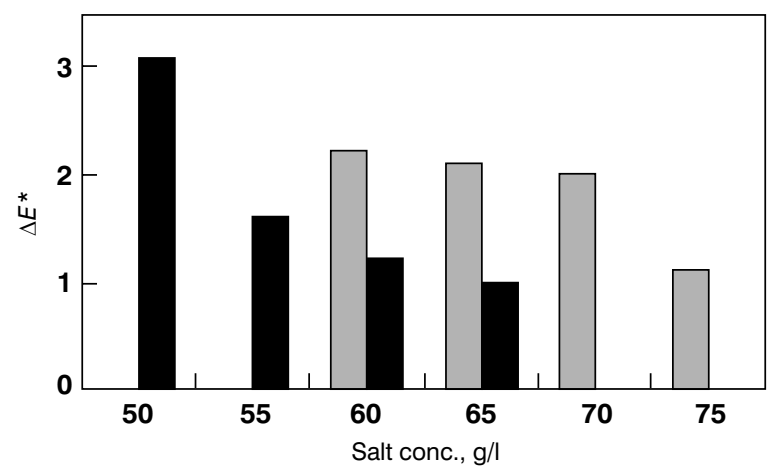

Figure 8 Dyeing in the bleaching bath increasing the salt concentration; for key see Figure 4

\section{Alkalinity}

As it was demonstrated in Figure 3, the alkalinity of the bleaching effluent was not high enough to produce good dyeing results alone, and further addition of soda ash was necessary. Even then, as it is illustrated in Table 1, the $\mathrm{pH}$ of the dyebath prepared with bleaching liquor did not reach the $\mathrm{pH}$ of the conventional dye bath. Alkalinity provokes 
ionisation of cellulose hydroxy groups and promotes the chemical reaction between the dye and the substrate.

The results of increasing the alkalinity in dyeings with catalase-treated bleaching effluent are shown in Figure 9. It is apparent that the colour difference of dyed samples was reduced slightly as the alkalinity of the dyebath was increased. However, an increase in alkalinity alone could not overcome the overall colour difference. This suggests that increasing both the alkali and electrolyte concentration slightly would result in successful dyeing in the bleaching effluent.

\section{Catalase concentration}

The applied commercial catalase-based product showed good efficiency at the high $\mathrm{pH}$ of the bleaching bath, which corresponds to the $\mathrm{pH}$ profile of catalase activity in phosphate buffer (incubation time $1 \mathrm{~h}$ at the corresponding $\mathrm{pH}$ ) (Figure 10). The exact quantity of the enzyme, sufficient for the decomposition of the hydrogen peroxide, had to be determined experimentally. It was found that if concen-

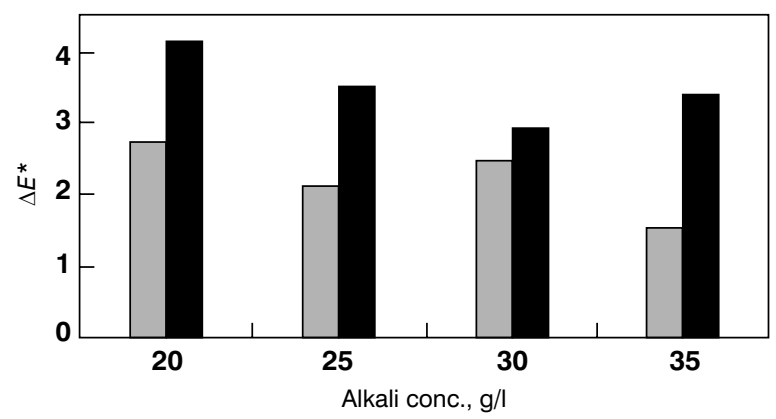

Figure 9 Dyeing in the bleaching bath increasing the alkalinity of the solution; for key see Figure 4

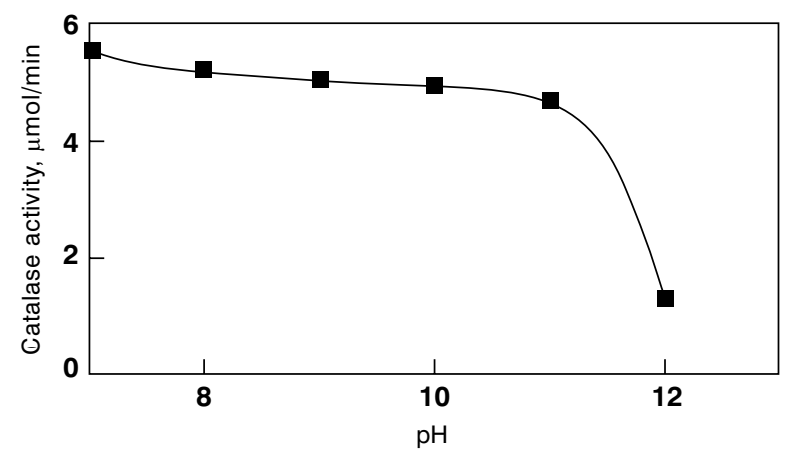

Figure $10 \mathrm{pH}$ profile of catalase activity

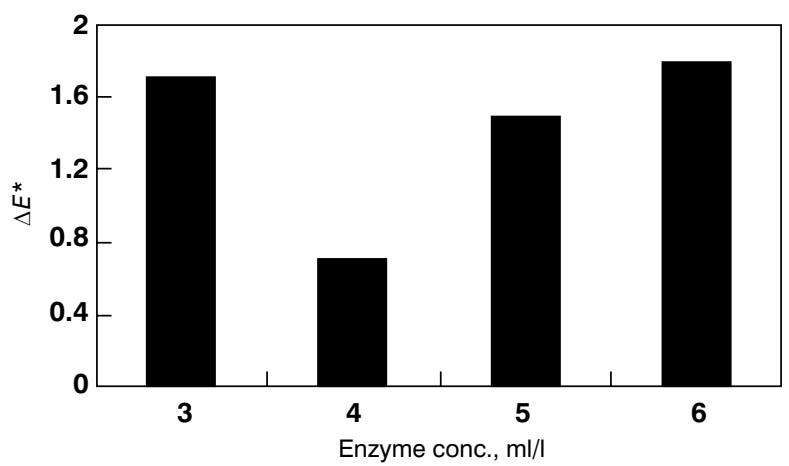

Figure 11 Dyeing in the bleaching bath treated with increasing amount of enzyme (CI Reactive Blue 198) trations above the optimum amount of enzyme were used, colour differences again were observed (Figure 11). This observation could be related to some interaction between the denatured enzyme and the reactive dye, resulting in dye aggregation and consequently reduced dye uptake.

\section{Conclusions}

In this study the potential to reuse the peroxide-containing bleaching effluent for dyeing with reactive dyes was investigated. Bleaching baths were treated prior to dyeing with catalase in order to convert the residual hydrogen peroxide, harmful to the colorants, to water and oxygen. The limitations of this approach could be considered with respect to two aspects in particular: the stability of the catalase at high temperature and $\mathrm{pH}$; and the influence of the bleaching bath composition on enzyme efficiency and on dye uptake. In order to prevent inactivation of the catalase, the bleaching bath was cooled down before addition of the enzyme and, if alkaline stability was a problem, also had to be neutralised.

Though the hydrogen peroxide was completely destroyed by the enzyme, the bleaching bath formulation caused unacceptable colour changes in the dyed fabrics. By varying the parameters of the dyeing process - dye, salt, alkali and enzyme concentrations - it was demonstrated that increasing the amount of these components to certain optimum levels, the colour difference could be reduced significantly and set to the defined colour difference interval. However, the overall influence of these parameters on the colour of the dyed substrate should be regarded as a result of their complex action. Selecting the optimum proportion between each of these parameters could be the key for successful dyeing in the bleaching bath, and thereby to realise considerable water and energy conservation, avoiding the extensive washing cycle after bleaching.

\section{References}

1. D M Lewis and J Yao, Book of Papers, International AATCC Conference, Philadelphia, US (1998) 375.

2. P Rhys and H Zollinger, The Theory of Coloration of Textiles, Ed. A Johnson, 2nd Edn (Bradford: SDC, 1995) 449.

3. U Sewekow, Melliand Textilber., 74 (1993) 153.

4. A Uygur, J.S.D.C., 113 (1997) 211.

5. E Akertek and L Tarhan, Appl. Biochem. Biotechnol., 50 (1995) 291.

6. L Goldstein and G Manecke, Applied Biochemistry and Bioengineering, Eds. L B Wingard, Jr, E Katchalski-Katzir and L Goldstein, Vol. 1 (New York: Academic, 1976) 23.

7. K-H Weible, US Patent, 5071439 (1991).

8. M M Bradford, Anal. Biochem., 72 (1976) 248.

9. H E Aebi, Catalase in Methods of Enzymatic Analysis, Ed. H U Bergmeyer and K Gawehn (Weinheim: Verlag Chemie $\mathrm{GmbH}, 1983) 273$.

10. D Steen, L'Industrie Textile (1998) 55.

11. W Bauman, R Brossman, B T Grobel, N Kleinemeier, M Krayer, A T Leaver and H P Oesch, Text. Chem. Colorist, 19 (1987) 21.

12. R W Harold, Text. Chem. Colorist 19 (1987) 23.

13. E R Trotman, Dyeing and Chemical Technology of Textile Fibres, 6th Edn (London: Arnold Publishers, 1990).

14. E R Trotman, Textile Scouring and Bleaching (London: Griffin, 1968).

15. M T Solas, C Vicente, L Xavier and M E Legaz, J. Biotechnol., 33 (1994) 63.

16. L N Guo, M Petit-Ramel, R Gautier, B Chabert and A Jacquet, J.S.D.C., 109 (1993) 213. 